\title{
Successful Use of Intercostal Muscle Flap in Cavitary Lung Lesions
}

\author{
Alaa Brik*, Abdel-Maged Salem, Khaled Mostafa \\ Departments of Cardiothoracic Surgery and Anesthesia, Zagazig University Hospital, Zagazig, Egypt. \\ Email: *alaabrik@yahoo.com
}

Received October $20^{\text {th }}$, 2012; revised November $26^{\text {th }}$, 2012; accepted December $8^{\text {th }}, 2012$

\begin{abstract}
Background: Lung cavities sometimes result from a number of pathological processes including suppurative necrosis, caseous necrosis, ischemic necrosis and cystic dilatation of lung structures. The aim of this study is to evaluate the use of intercostals muscle flap as a successful method to fill the lung cavity for reduction of symptoms and treatment of patients presented with symptomatic pulmonary cavity and to avoid the risk of pulmonary resection. Methods: This is a prospective study conducted between 2009 to 2012, in department of cardiothoracic surgery, Zagazig University Hospital. The study included 32 patients suffering from cavitary lung lesions divided into two groups, group (A): 14 patients treated by using intercostal muscle flap to fill the defect after Cavernostomy without lung resection; and group (B): 18 patients treated by traditional methods by lung resection. Patients with high risk of lung resection, suspicion of dense adhesion, symptomatic chronic lung abscess and patients with bad pulmonary function tests were included in group (A). Results: 20 patients were male and 12 were females in both groups, the large numbers of cases were lung abscess in group A (4 cases 28.5\%) followed by Aspergilloma and TB cavity (3 cases 21.4\%). Hemoptysis, persistent cough and expectoration were the main presentation of our patients. Poor pulmonary function was significant finding in group A (7 cases 50\%). Complications reported in our study were bleeding, recurrent symptoms and one case mortality in group B after Pneuomenectomy. Conclusion: Using the intercostal muscle flap implanted inside the lung cavity after cavernostomy is a successful alternative curative method especially in cases with high risk of lung resection.
\end{abstract}

Keywords: Lung Resection; Intercostal Muscle Flap; Lung Cavities

\section{Introduction}

Cavities are frequent manifestations of a wide variety of pathological processes involving the lung. A cavity is the result of any of a number of pathological processes including suppurative necrosis, caseous necrosis, ischemic necrosis, cystic dilatation of lung structures [1]. Lesions may be solitary or multiple, and they usually have thick walls with irregular margins [2]. Lung cavitation is rare in cases of bronchogenic carcinoma and most of the cavitating lung carcinomas are of squamouscell origin (82\%) [3]. Cavitation seems to occur as a result of tumor ischemia and infarction following development of an abscess distal to neoplastic bronchial obstruction [4]. The aim of this study is to evaluate the use of intercostal muscle flap as a successful method to reduce symptoms and treatment of patients presented with symptomatic pulmonary cavity, to avoid the risk of pulmonary resection and unnecessary lung resection.

\footnotetext{
"Corresponding author.
}

\section{Patients and Methods}

\subsection{Study Population}

This is a prospective study conducted between 2009 to 2012, in the department of cardiothoracic surgery, Zagazig University Hospital. The study included 32 patients suffering from cavitary lung lesions divided into two groups according to the type of treatment, group (A) 14 patients with high risk of lung resection or there is needs to preserve lung tissue in the treatment was by using intercostal muscle flap to fill the defect after cavernostomy, without lung resection, to limit the air leaks, decrease the hospital stay. Group (B) 18 patients treated by traditional methods of lung resection.

\subsection{Pre-Operative Assessment}

All patients were submitted to history taking and clinical examination with full laboratory investigation. Radiological finding were collected from X-ray chest postroanterior and lateral view, CT chest (Figure 1). Pulmonary function tests were done for all patients. Broncho- 


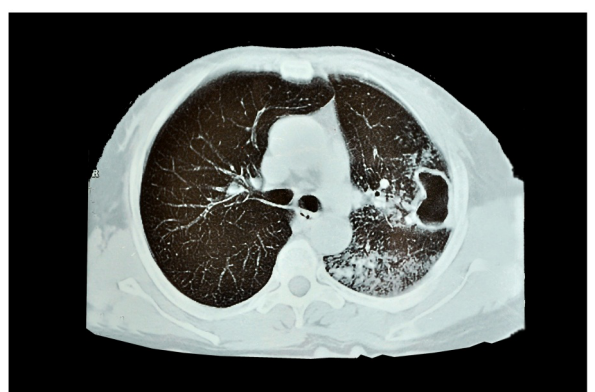

Figure 1. CT chest show cavitary lesion treated by intercostal muscle flap.

scopy was performed for some cases as preoperative assessments. Patients with high risk of lung resection, suspicion of dense adhesion, symptomatic lung abscess not responding to medical treatment, bilateral lung cavity and patients with bad pulmonary function tests were included in group (A), while patients with malignant cavities were excluded from this group.

\subsection{Surgical Technique}

The intercostal muscle (ICM) flap is easily harvested. The flap harvested before placing a rib spreader. The intercostal muscle and neurovascular pedicle are separated from the inferior aspect of corresponding rib using a periosteal elevator. The ICM is then freed from the underside of the superior rib taking great care to preserve the intercostal neurovascular bundle, the periosteal elevator is preferred over cautery to avoid thermal injury to the pedicle but we used both of them. In some cases we used two intercostal muscles in the same patients we harvest the muscle in upper or lower chest according to the site of the cavity, the intercostal muscle cut at its anterior or posterior end according to the distance between the pedicle and the cavity. We wrap the flap in moist warm gauze. Assessment of muscle flap viability and care should be taken to avoid torsion of the flap. The pulmonary cavity were assessed and localize its sit, then opened by cautery to avoid bleeding, evacuation the content of the cavity, curettage its wall then test for broncho-pleural fistula which if found we closed it by figure of eight sutures by Vicryl $3^{\circ}$, then the intercostal muscles was cut anterior or posterior according to the site of the cavity and buttressed inside the cavity, apply simple and separate sutures to fix the ICM inside the cavitary wall then we approximate the edges of the cavity with muscle inside (Figure 2). Patients in group B treated by resection of the cavity with part of the lung either lobe, segment or wedge resection usually we used ICM flap, pericardia flap or azygos vain flap to cover the bronchial stump.

\subsection{Anesthetic Technique}

Induction of anesthesia may be conducted in a standard

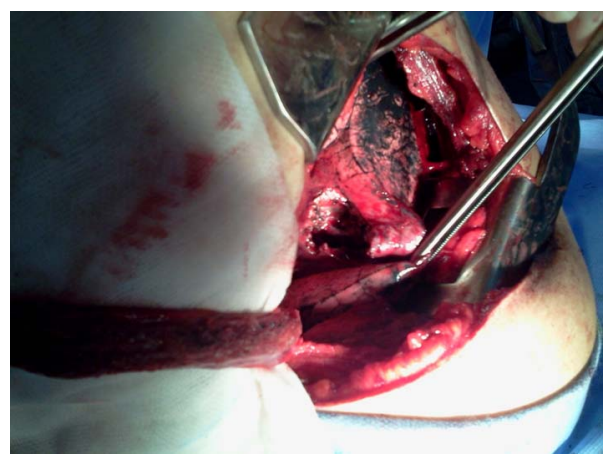

Figure 2. Show cavitary lesion of the upper lobe (lung abscess) and the pedicle intercostal muscle flap (ICM).

manner with intravenous agent as propofol plus opiate as fentanyl and non depolarizing muscle relaxant as pancuronium. Subsequent intubation is usually with a double lumen endotracheal tube (DLT). These tubes allow each lung to be independently ventilated or collapsed and reexpanded. The DLT should be checked clinically and with a fibro-optic broncoscope.

\subsection{Patient Follow-Up}

Patients are seen in the outpatient's clinic weekly after discharge for one month. They are subsequently followed-up at 3-month intervals for the first year with chest $\mathrm{X}$-rays in the clinic, and annually thereafter. Data were collected for each patient including time of chest tube removal, discharge from the hospital, occurrence of complications, need for transfusion, reoperation, readmission, and recurrent symptoms.

\subsection{Statistical Analysis}

Results were analyzed using SPSS version 15.0 (Statistical Package for Social Science, SPSS Inc., Chicago, IL, USA). Continuous variables, such as age were expressed as the mean \pm S.D. and compared by unpaired t-test. Categorical variables were expressed by number (n) and frequencies (\%). The $\chi^{2}$-test was used to compare the proportions. A P value of $<0.05$ was considered statisticcally significant.

\section{Results}

32 patients suffering from cavitary lung lesions divided into two groups group (A) 14 patients with high risk for lung resection due to bad pulmonary function, suspicion of dense adhesion or small lung cavity and we want to preserve the lung parenchyma treated by using intercostal muscle flap to fill the defect after cavernostomy, group (B) 18 patients treated by traditional lung resection. 20 patients were male and 12 were females in both groups, the large numbers of cases were lung abscess in group $\mathrm{A}$ (4 cases $28.5 \%$ ) followed by Aspergilloma and TB cavity 
(3 cases 21.4\%). Hemoptysis, persistent cough and expectoration were the main presentation of our patients. Poor pulmonary function was significant finding in group A which presents (7 cases 50\%) Table 1. Two intercostal muscles were used in 2 cases in group A and one intercostal muscle was used in other all cases of group A while in group B lobectomy is the most common surgical procedure performed in this group 13 cases (72.2\%) Table 2. Complications reported in our study were bleeding, recurrent symptoms and one case mortality in group B after Pneuomenectomy due to prolonged mechanical ventilation and multiorgans failure, bleeding was the most common complication in both group which occurs in 9 cases in both groups (28.1\%). Recurrent of hemoptysis occurs in one case in both groups because the lesions were bilateral, no broncho-pleural fistula (BPF) reported in group A, one case of (BPF) recorded in group B after post lobectomy empyema which treated by latissimus muscle flap Table 3.

\section{Discussion}

Many times after thoracic exploration for surgical treatment of lung cavity we found either small or peripheral lesion, and lung resection considered harmful and unnecessary for the patient so we thought to replace traditional lung resection for peripheral cavitary lung lesions by using pedicle intercostal muscle flap buttressed inside the cavity after cavernostomy.

Table 1. Patient's characteristics.

\begin{tabular}{|c|c|c|c|}
\hline & $\begin{array}{l}\text { Group A } \\
\text { (No. 14) }\end{array}$ & $\begin{array}{l}\text { Group B } \\
\text { (No. 18) }\end{array}$ & $\mathrm{p}$ value \\
\hline Age & $48 \pm 6$ & $43 \pm 11$ & 0.21 \\
\hline Male & $9(64.2 \%)$ & $11(61.1 \%)$ & - \\
\hline Female & $5(35.7 \%)$ & 7 (38.8\%) & 0.85 \\
\hline Lung abscess & $4(28.5 \%)$ & 7 (38.8\%) & 0.71 \\
\hline Aspergilloma & $3(21.4 \%)$ & $1(5.5 \%)$ & 0.29 \\
\hline Bronchiectasis & $2(14.2 \%)$ & $5(27.7 \%)$ & 0.42 \\
\hline T. B. Cavity & $3(21.4 \%)$ & 2 (11.1\%) & 0.63 \\
\hline Polycystic lung & $1(7.1 \%)$ & $2(11.1 \%)$ & 0.81 \\
\hline Hydrated cyst & $1(7.1 \%)$ & $1(5.5 \%)$ & 0.58 \\
\hline Hemoptysis & $8(57.1 \%)$ & $11(61.1 \%)$ & 0.82 \\
\hline Expectoration & $5(35.7 \%)$ & $9(50 \%)$ & 0.41 \\
\hline Persistent cough & $6(42.8 \%)$ & $10(55.5 \%)$ & 0.47 \\
\hline Empyema with BPF & $1(7.1 \%)$ & $1(5.5 \%)$ & 0.58 \\
\hline Diabetes mellitus & $5(35.7 \%)$ & $8(44.4 \%)$ & 0.61 \\
\hline Bad pulmonary function & $7(50 \%)$ & $3(16.6 \%)$ & 0.04 \\
\hline
\end{tabular}

Table 2. Operative procedures.

\begin{tabular}{cccc}
\hline & Group A (No. 14) & Group B (No. 18) & p value \\
\hline $\begin{array}{c}\text { Intracavitary ICM flap } \\
\text { (one muscle) }\end{array}$ & $12(85.7 \%)$ & 0 & 0.001 \\
$\begin{array}{c}\text { Intracavitary ICM flap } \\
\text { (two muscles) }\end{array}$ & $2(14.2 \%)$ & 0 & 0.81 \\
Lobectomy & 0 & $13(72.2 \%)$ & 0.001 \\
Bilobectomy & 0 & $1(5.5 \%)$ & 0.89 \\
Segmentectomy & 0 & $1(5.5 \%)$ & 0.89 \\
Wedge resection & 0 & $1(5.5 \%)$ & 0.89 \\
Pneuomenectomy & 0 & $2(11.1 \%)$ & 0.49 \\
\hline
\end{tabular}

ICM: intercostal muscle.

Table 3. Complications.

\begin{tabular}{cccc}
\hline & Group A (No. 14) & Group B (No. 18) & p value \\
\hline Bleeding & $3(21.4 \%)$ & $6(33.3 \%)$ & 0.69 \\
Recurrent hemoptysis & $1(7.1 \%)$ & $1(5.5 \%)$ & 0.58 \\
Empyema & $1(7.1 \%)$ & $2(11.1 \%)$ & 0.81 \\
Broncho-plural fistula & 0 & $1(5.5 \%)$ & 0.89 \\
Recurrent expectoration & $1(7.1 \%)$ & $2(11.1 \%)$ & 0.89 \\
Death & 0 & $1(5.5 \%)$ & 0.89 \\
\hline
\end{tabular}

Mycobacterium tuberculosis generally has the highest prevalence of cavities among persons with pulmonary disease [5]. Tuberculosis is the cause of cavitary lung lesions in $40.4 \%$ of the cases with significant high tuberculous lesions in complex aspergilloma [6]. Other pathogens, such as Klebsiella pneumonia, are associated with extensive pyogenic lung necrosis and frequent cavitation [7]. Lung abscess is another relatively common bacterial cause of cavitary lung lesions and most patients have one or more predisposing risk factors [8]. In our series the large numbers of cases were lung abscesses followed by tuberculous cavitary lesions. The most clinical presentation pushing us for surgical treatment is hemoptysis, persistent cough and no response to medical treatment, some authors recommend early surgical resection of tuberculous cavities to avoid life-threatening hemoptysis [9]. In the present study we facing various degree of hemoptysis from massive to recurrent and the surgical treatment is curative in all our cases, with recurrence in one cases in group $\mathrm{A}$, because the patient was suffering from bilateral bronchiectasis. Major risk factors for the lesions were diabetes mellitus and major risk factor to avoid lung resection was bad pulmonary functions tests. The concept of using a viable, vascularized muscle flap in chronic and infective BPF is well established and initial report by Hallows et al. in 2004 using a serratus 
anterior muscle digitation flap in the management of pyopneumothorax in children [10]. We perform the same concept by using intercostal muscle flap in management of peripheral cavitary lung lesions either single or double flap according to the size and location of the cavity, single intercostal muscle flap was the main procedure performed in our series represent $(85.7 \%)$ of cases. The technique was simple and easy to performed, post-operative complications were low and accepted in comparison to group B, like recurrent hemoptysis and expectoration which were not related to procedure but lesions related factors as bilateral lesions or persistent risk factors. Post-operative broncho-pleural fistula (BPF) which is the most serious complication not recorded in group A, but recorded in pulmonary resection cases after lobectomy. Intraoperative bleeding was limited in cases of muscle flap but observed in group B. Jester et al. reported early surgical intervention with insertion of a serratus anterior muscle digitation flap in cases with empyema and B-P fistula secondary to necrotizing pneumonia in children is effective and safe and avoids morbidity associated with conservative management and necrotic lung resection surgery [11]. There have been no reports of peripheral lung cavity reconstruction using intercostal muscle flap, but there are some attempts to use other chest wall muscles in management of empyema space or broncho- pleural fistula as the paraspinous muscle flap, serratus anterior muscle digitation flap, latissimus dorsi flap and pectoralis major muscle flap [11-13]. No mortality in our patients treated by intercostal muscle flap either intraoperative or in follow up period in spit of poor pulmonary function tests in $50 \%$ of cases, another advantages for the procedures were short hospital stay, early chest tube removal in comparison to lung resection group and less intraoperative complications.

\section{Conclusion}

Using the intercostal muscles flap implanted inside the lung cavity After cavernostomy are easy and curative methods for symptomatic cavitary lung lesions especially in cases with high risk of lung resection or small chronic lung cavity with attempt to preserve lung tissues to avoid unnecessary lung resection.

\section{REFERENCES}

[1] V. Kumar, A. K. Abbas, N. Fausto, S. L. Robbins and R. S. Cotran, "Robbins and Cotran Pathologic Basis of Disease,” Elsevier Saunders, Philadelphia, 2005.

[2] J. Andreu, J. Cáceres, E. Pallisa and M. M. Rodriguez,
"Radiological Manifestations of Pulmonary Tuberculosis,” European Journal of Radiology, Vol. 51, No. 2, 2004, pp. 139-149. doi:10.1016/j.ejrad.2004.03.009

[3] M. Berger and J. R. Thompson, "Cavitary Carcinomatosis of the Lungs,” Chest Journal, Vol. 52, No. 1, 1967, pp. 106-111. doi:10.1378/chest.52.1.106

[4] M. R. Chaudhuri, "Primary Pulmonary Cavitating Carcinomas,” Chest, Vol. 28, No. 3, 1973, pp. 354-366.

[5] J. E. Golub, S. Bur, W. A. Cronin, S. Gange, N. Baruch, G. W. Comstock and R. E. Chaisson, "Delayed Tuberculosis Diagnosis and Tuberculosis Transmission," International Journal of Tuberculosis and Lung Disease, Vol. 10, No. 1, 2006, pp. 24-30.

[6] A. Brik, A. Salem, A. Kamal, M. Abdel-Sadek, M. Essa, M. El Sharawy, A. Deebes and K. A. Bary, "Surgical Outcome of Pulmonary Aspergilloma,” European Journal Cardio-Thoracic Surgery, Vol. 34, No. 4, 2008, pp. 882885. doi:10.1016/j.ejcts.2008.06.049

[7] W. K. Moon, J. M. Im, K. M. Yeon and M. C. Han, "Complications of Klebsiella Pneumonia: CT Evaluation," Journal of Computer Assisted Tomography, Vol. 19, No. 2, 1995, pp. 176-181. doi:10.1097/00004728-199503000-00002

[8] J. M. Hammond, P. D. Potgieter, D. Hanslo, H. Scott and D. Roditi, "The Etiology and Antimicrobial Susceptibility Patterns of Microorganisms in Acute Community-Acquired Lung Abscess," Chest, Vol. 108, No. 4, 1995, pp. 937-941. doi:10.1378/chest.108.4.937

[9] A. Brik, A. M. Salema, A. Shoukry and W. Shouman, "Surgery for Hemoptysis in Various Pulmonary Tuberculous Lesions: A Prospective Study," Interactive CardioVasc Thoracic Surgery, Vol. 13, No. 3, 2011, pp. 276279. doi:10.1510/icvts.2011.270991

[10] M. R. Hallows and D. H. Parikh, "Surgical Management of Children with Pyopneumothorax: Serratus Anterior Digitation Flap,” Journal of Pediatric Surgery, Vol. 39, No. 7, 2004, pp. 1122-1124.

doi:10.1016/j.jpedsurg.2004.03.074

[11] I. Jester, A. Nijran, M. Singh and D. H. Parikh, "Surgical Management of Bronchopleural Fistula in Pediatricempyema and Necrotizing Pneumonia: Efficacy of the Serratus Anterior Muscle Digitation Flap,” Journal of Pediatric Surgery, Vol. 47, No. 7, 2012, pp. 1358-1362. doi:10.1016/j.jpedsurg.2011.12.012

[12] M. Takeuchi and H. Sakurai, "Paraspinous Muscle Flap for the Treatment of an Empyema Cavity,” Journal of Plastic, Reconstructive \& Aesthetic Surgery, Vol. 65, No. 6, 2012, pp. 824-826.

[13] F. M. Smolle-Juettner, G. Pierer, F. Schwarzl, H. Pinter, B. Ratzenhofer, G. Prause and G. Friehs, "Life-Saving Muscle Flaps in Tracheobronchial Dehiscence Following Resection or Trauma,” European Journal Cardio-Thoracic Surgery, Vol. 12, No. 3, 1997, pp. 351-355. doi:10.1016/S1010-7940(97)00180-2 